\title{
Short-term effects of right atrial, right ventricular apical, and atrioventricular sequential pacing on myocardial oxygen consumption and cardiac efficiency in patients with coronary artery disease
}

Zenon S Kyriakides, Aias Antoniadis, Efstathios Iliodromitis, Nickolaos Michelakakis, Dimitrios T Kremastinos

\begin{abstract}
Objective-To investigate the short-term effects of atrial, atrioventricular, and ventricular pacing on myocardial oxygen consumption, myocardial blood flow, and cardiac efficiency in patients with coronary artery disease.

Design-Prospective study that started at the end of diagnostic coronary angiography in 13 patients and was performed during atrial, atrioventricular, and ventricular pacing for $5 \mathrm{~min}$, in random order, at 20 beats/min more than the heart rate of the patient's positive exercise test. A Baim thermodilution catheter in the coronary sinus was used to measure myocardial blood flow and oxygen consumption and a pacing electrode at the right ventricular apex and a catheter in the pulmonary artery were used to estimate cardiac output.

Setting-Referral cardiology centre.

Patients-13 patients with coronary artery disease (mean (SD) age 53(5) years). All the patients had a positive exercise test and most of them (77\%) had left anterior descending coronary artery disease.
\end{abstract}

Results-Mean (SD) cardiac output increased by $0.5(1.6) 1 / \mathrm{min}$ during atrial pacing, increased by $0 \cdot 1$ (1) $1 / \mathrm{min}$ during atrioventricular pacing, and decreased by $0 \cdot 8(1 \cdot 2) 1 / \mathrm{min}$ during ventricular pacing $(P=0.01 v$ atrial pacing, $P=0.03 v$ atrioventricular pacing). Diastolic pulmonary pressure increased by 6(4) $\mathrm{mm}$ $\mathrm{Hg}$ during atrial pacing, by $8.6(4) \mathrm{mm} \mathrm{Hg}$ during ventricular pacing $(P=0.02 v$ atrial pacing), and by $7 \cdot 5(4 \cdot 7) \mathrm{mm} \mathrm{Hg}$ during atrioventricular pacing. Changes in myocardial oxygen consumption and cardiac efficiency during the different pacing modes were similar.

Conclusion-Atrial, atrioventricular, and ventricular pacing had similar shortterm effects on myocardial oxygen consumption, myocardial blood flow, and cardiac efficiency in patients with coronary artery disease. Ventricular pacing, however, did not increase cardiac output.

(Br Heart f 1994;71:536-540)

Whereas there have been many studies of the haemodynamic effects of cardiac pacing, ${ }^{1-4}$ little is known about its effect on coronary circulation and myocardial ischaemia. Studies of myocardial oxygen consumption during atrial and ventricular stimulation gave conflicting results. ${ }^{56}$ The effects of atrial pacing have not been systematically compared with those of atrioventricular sequential and right ventricular pacing. We studied the short-term effects of those pacing modes on myocardial ischaemia, myocardial oxygen consumption, and cardiac efficiency in patients with coronary artery disease.

\section{Patients and methods}

PATIENTS

We studied 13 men (mean (SD) age 53(5), range (range 43-62 years) with typical exertional chronic stable angina (8 class 3 of the Canadian Cardiovascular Society and 5 class 2) and a positive treadmill exercise stress test ( $>1 \mathrm{~mm}$ horizontal or downsloping ST segment depression $80 \mathrm{~ms}$ after the J point). All had angiographically significant stenosis ( $>$ $70 \%$ reduction in luminal diameter) of at least one of the three major epicardial coronary arteries (table 1). All medication, except sublingual nitrates, was stopped 72 hours before the study. Informed consent was obtained and the study was approved by the hospital ethics committee. Exclusion criteria were old or acute myocardial infarction, unstable angina, systemic hypertension, bundle branch block, any acute illness, and left main coronary artery disease.

METHODS

All the patients had routine diagnostic cardiac catheterisation (Seldinger) at the time of the study. They were fasted and no premedication was given.

After the end of the cardiac catheterisation a 7 French Baim coronary sinus thermodilution catheter (Electro-Catheter, Rahway, New Jersey) was inserted into the left subclavian vein and was advanced into the coronary sinus under fluoroscopic control. The position was checked by injection of a small quantity of radiographic contrast medium (Urografin $75 \%$ ), and we ensured that the tip of the catheter was distal to the valve of Vieussen. Oxygen saturation was measured in the coronary sinus by a blood analyser (Corning 178, Midfield, Massachusetts) before the pacing test started and immediately before it ended.

A pacing electrode was inserted percuta-
Athens General Z S Kyriakides A Antoniadis E Iliodromitis 13 October 1993 
Table 1 Clinical characteristics of the patients

\begin{tabular}{|c|c|c|c|c|c|c|c|c|}
\hline $\begin{array}{l}\text { Case } \\
\text { No }\end{array}$ & $\begin{array}{c}\text { Age } \\
(y r)\end{array}$ & $C A D$ & $\begin{array}{l}\text { CSS } \\
\text { class }\end{array}$ & $\begin{array}{l}\text { Pacing } H R \\
\text { (beats/min) }\end{array}$ & $\begin{array}{l}\text { Duration } \\
\text { of pacing } \\
\text { (min) }\end{array}$ & $\begin{array}{l}P-Q \\
\text { during } \\
\text { A pacing }\end{array}$ & $\begin{array}{l}P-Q \text { during } \\
A-V \\
\text { pacing }\end{array}$ & $\begin{array}{l}P-Q \\
\text { at rest }\end{array}$ \\
\hline $\begin{array}{l}1 \\
2 \\
3 \\
4 \\
5 \\
6 \\
7 \\
8 \\
9 \\
10 \\
11 \\
12 \\
13\end{array}$ & $\begin{array}{l}49 \\
55 \\
47 \\
62 \\
53 \\
51 \\
60 \\
57 \\
58 \\
55 \\
55 \\
49 \\
43\end{array}$ & $\begin{array}{l}\text { 3-VD } \\
\text { LAD,Cx } \\
\text { 3-VD } \\
\text { LAD } \\
\text { LAD,Cx } \\
\text { LAD,RCA } \\
\text { 3-VD } \\
\text { RCA,Cx } \\
\text { 3-VD } \\
\text { LAD } \\
\text { LAD,Cx } \\
\text { RCA,Cx } \\
\text { RCA,Cx }\end{array}$ & $\begin{array}{l}3 \\
3 \\
2 \\
3 \\
2 \\
3 \\
3 \\
3 \\
2 \\
2 \\
2 \\
3 \\
3\end{array}$ & $\begin{array}{l}145 \\
155 \\
135 \\
125 \\
130 \\
145 \\
110 \\
120 \\
135 \\
145 \\
135 \\
155 \\
125\end{array}$ & $\begin{array}{l}5 \\
3 \\
5 \\
3 \\
5 \\
5 \\
3 \\
5 \\
5 \\
3 \\
3 \\
5 \\
5\end{array}$ & $\begin{array}{l}210 \\
190 \\
190 \\
190 \\
210 \\
200 \\
200 \\
160 \\
250 \\
140 \\
180 \\
200 \\
160\end{array}$ & $\begin{array}{l}120 \\
125 \\
120 \\
145 \\
120 \\
120 \\
100 \\
110 \\
100 \\
110 \\
175 \\
115 \\
120\end{array}$ & $\begin{array}{l}208 \\
190 \\
180 \\
170 \\
172 \\
200 \\
165 \\
160 \\
210 \\
140 \\
150 \\
160 \\
160\end{array}$ \\
\hline Mean (SD) & 53 & & & $135(13)$ & & $190(27)$ & $121(20)$ & $174(22)$ \\
\hline
\end{tabular}

Al, atrial; A-V, atrioventricular; CAD, coronary artery disease; CCS, Canadian Cardiovascular Society angina classification; Cx1, left circumflex artery; HR, heart rate; LAD, left anterior descending artery; RCA, right coronary artery; VD, vessel disease.

neously into the apex of the right ventricle from the right femoral vein. A Sones type catheter was inserted into the pulmonary artery from the right femoral vein to monitor pulmonary artery pressure and take blood samples before and during the tests.

Right atrial, right ventricular, and atrioventricular pacing were performed on each patient. The pacing rate test was 20 beats/min more than the heart rate reached by the patient during the exercise stress test that was performed before cardiac catheterisation. A brief pacing test was done first at the predetermined rate to check whether a positive Wenckebach phenomenon developed. When it did the patient was excluded from the study. The pacing mode with which we began the study on every patient was randomly chosen. During atrioventricular pacing we reduced the atrioventricular delay until transient electrocardiographic left bundle branch block developed. Each pacing mode lasted 5 min, with a 5 min rest period between each of the modes.

The pacing test was stopped if severe pain developed or at the patient's request. In this event the second and third pacing tests were terminated at the same time as the first one.

The systemic blood pressure was continuously monitored and recorded through the femoral artery sheath during each pacing test. The development of chest pain was also noted.

Cardiac output was measured by the Fick technique. Total oxygen consumption was estimated from tables. ${ }^{7}$ We measured myocardial blood flow by the thermodilution technique $^{8}$ using the proximal thermistor of the catheter. Myocardial oxygen consumption $\left(\mathrm{MV்}_{2}\right)$ was estimated by the formula:

$$
\begin{gathered}
\mathrm{MV}_{\mathrm{O}_{2}}=\mathrm{CO} \times\left(\text { arterial } \mathrm{O}_{2} \text { saturation - venous } \mathrm{O}_{2}\right. \\
\text { saturation } \times \mathrm{Hb} \times 1.36\left(\mathrm{ml} \mathrm{O} \mathrm{O}_{2} / \mathrm{min}\right),
\end{gathered}
$$

where $\mathrm{CO}$ is cardiac output in $1 / \mathrm{min}$ and $\mathrm{Hb}$ was haemoglobin in $\mathrm{g} / 100 \mathrm{ml}$. Cardiac efficiency was calculated from the equation: Cardiac efficiency $=$ External cardiac work $/ \mathrm{MV}^{\circ}{ }_{2}$
Efficiency $(\%)=(\mathrm{SAP} \times \mathrm{CO} \times \mathrm{F}) / \mathrm{MV}_{\mathrm{O}_{2}}$

where $F=0.632$ and $\mathrm{SAP}=$ systolic aortic pressure in $\mathrm{mm} \mathrm{Hg}$.

\section{STATISTICAL ANALYSIS}

All data are expressed as mean (SD). For interpacing comparisons we used Friedman two-way analysis by ranks and for intrapacing comparisons we used the Wilcoxon rank test.

\section{Results}

Electrocardiographic left bundle branch block developed in all patients during atrioventricular and ventricular pacing. No complication developed during or after the study. We started with atrial pacing in four patients, with ventricular pacing in four and with atrioventricular pacing in five.

All but five of the patients were paced for 5 minutes. These five patients were paced for 3 min because of severe pain; they were also paced for $3 \mathrm{~min}$ for the second and third pacing tests. The heart rate increased to the same extent (at 57 beats/min more than the resting heart rate) during the three pacing tests. Atrioventricular delay increased significantly $(\mathrm{P}<0.005)$ from rest to atrial pacing (table 1$).$

In five patients chest pain did not develop; in seven it developed during atrial pacing, in seven it developed during atrioventricular pacing, and in eight it developed during ventricular pacing. After each pacing test angina and electrocardiographic changes disappeared in less than a minute in all the patients studied, so the 5 minute interval between pacing tests was adequate.

Systolic pulmonary pressure increased by 3(6) $\mathrm{mm} \mathrm{Hg}$ during atrial pacing, by $6(5) \mathrm{mm}$ $\mathrm{Hg}$ during ventricular pacing, and by $3(5)$ $\mathrm{mmHg}$ during atrioventricular pacing. Systolic blood pressure decreased by $7(8) \mathrm{mm}$ $\mathrm{Hg}$, by $15(22) \mathrm{mm} \mathrm{Hg}$, and by $6(13) \mathrm{mm} \mathrm{Hg}$ respectively. Diastolic blood pressure increased by $9(8) \mathrm{mm} \mathrm{Hg}$, by $9(12) \mathrm{mm} \mathrm{Hg}$, and by $13(8) \mathrm{mm} \mathrm{Hg}$ respectively. None of the differences between the pacing modes was statistically significant (table 2).

Cardiac output increased by $0.5(1 \cdot 6) 1 / \mathrm{min}$ during the atrial pacing test, decreased by $0 \cdot 8(1 \cdot 2) 1 / \mathrm{min}$ during ventricular pacing $(\mathrm{P}=$ $0.01 v$ atrial pacing, $\mathrm{P}=0.03 v$ atrioventricular pacing), and increased by $0 \cdot 1$ (1) $1 / \mathrm{min}$ during the atrioventricular pacing test. Diastolic pul- 
Table 2 Variables at rest and during different pacing modes.

\begin{tabular}{|c|c|c|c|c|}
\hline & Atrial pacing & $\begin{array}{l}\text { Ventricular } \\
\text { pacing }\end{array}$ & $A-V$ pacing & Rest \\
\hline $\begin{array}{l}\mathrm{SPP}(\mathrm{mm} \mathrm{Hg}) \\
\mathrm{CO}(\mathrm{l} / \mathrm{min})\end{array}$ & $\begin{array}{l}34(9) \\
7 \cdot 0(2 \cdot 2)\end{array}$ & $37(8)$ & $35(12)$ & $31(7)$ \\
\hline $\mathrm{DPP}(\mathrm{mm} \mathrm{Hg})$ & $19(7)$ & $22(8) \dagger$ & $\begin{array}{l}6 \cdot 6(1 \cdot 2) \\
20(9)\end{array}$ & $\begin{array}{l}6 \cdot 6(1 \cdot 4) \\
13(5)\end{array}$ \\
\hline SBP $(\mathrm{mm} \mathrm{Hg})$ & $146(23)$ & $140(33)$ & $148(20)$ & $153(24)$ \\
\hline $\mathrm{DBP}(\mathrm{mm} \mathrm{Hg})$ & $94(14)$ & $93(15)$ & $96(14)$ & $84(14)$ \\
\hline $\begin{array}{l}\mathrm{MVo}_{2} \\
\left(\mathrm{mlo}_{2} / \mathrm{min}\right)\end{array}$ & $313(107)$ & $286(70)$ & $284(57)$ & $193(47)$ \\
\hline HR (b/min) & $136(11)$ & $136(11)$ & $136(13)$ & $78(10)$ \\
\hline $\mathrm{CSO}_{2} \mathrm{Sat}(\%)$ & $30(6)$ & $27(7)$ & $28(8)$ & $33(2)$ \\
\hline $\mathrm{MBF}(\mathrm{mi} / \mathrm{min})$ & $234(90)$ & 206(49) & $206(46)$ & $151(36)$ \\
\hline Efficiency (\%) & $2.39(0.92)$ & $1.86(0.58)$ & $2 \cdot 30(0.63)$ & $3 \cdot 50(1 \cdot 19)$ \\
\hline
\end{tabular}

monary pressure increased by $6(4) \mathrm{mm} \mathrm{Hg}$ during atrial pacing, by $8.6(4) \mathrm{mm} \mathrm{Hg}$ during ventricular pacing ( $P=0.02 v$ atrial pacing), and by $7.5(4 \cdot 7) \mathrm{mm} \mathrm{Hg}$ during atrioventricular pacing.

Myocardial oxygen consumption increased by $121(96) \mathrm{ml} / \mathrm{min}$ during atrial, by 83 (66) $\mathrm{ml} / \mathrm{min}$ during ventricular, and by $88(41)$ $\mathrm{ml} / \mathrm{min}$ during atrioventricular pacing. Coronary sinus oxygen saturation decreased by $3(6) \%$, by $6(7) \%$, and by $4(7) \%$ respectively. Myocardium blood flow increased by $83(78) \mathrm{ml} / \mathrm{min}$, by $49(46) \mathrm{ml} / \mathrm{min}$, and by $56(39) \mathrm{ml} / \mathrm{min}$ respectively. Cardiac efficiency decreased by $(1 \cdot 2) \%$, by $1 \cdot 5(0 \cdot 9) \%$, and by $1 \cdot 1(0.9) \%$ respectively. None of the differences in these changes between the different pacing modes was significant. Cardiac efficiency tended to be lower during ventricular pacing (Friedman analysis, $\mathrm{t}=4 \cdot 7, \mathrm{P}=0.09$ ).

\section{Discussion}

There is concern that some of the newer pacing modes may worsen angina in patients with coronary artery disease because they increase heart rate and myocardial oxygen demand. In patients with coronary artery disease it is crucial to know the effects of the different pacing modes on myocardial oxygen consumption and cardiac efficiency. The patients were supine during the pacing tests and heart rate, systemic blood pressure, and double product (a good predictor of myocardial oxygen) consumption were similar during all three tests. In earlier studies there were shortterm and long-term improvements in haemodynamic performance when ventricular pacing was changed to atrioventricular pacing. ${ }^{2910}$ We found that cardiac output increased during atrial and atrioventricular pacing but decreased during ventricular pacing. In our patients the pacing rate was the same during all the pacing modes, so the difference in cardiac output was not heart rate dependent but was probably the result of a lack of the atrioventricular sequence during ventricular pacing. Atrioventricular synchrony augments ventricular filling and cardiac output through the Frank-Starling relation, improves venous return, and assists closure of the atrioventricular valve. The value of atrioventricular synchrony is of considerable importance to patients with coronary artery disease, who tolerate the loss of atrial contraction poorly. Kruse et al showed similar longterm and short-term haemodynamic effects for atrioventricular pacing whereas with ventricular pacing haemodynamic function deteriorated with time. ${ }^{2}$ We investigated only the short-term effects of pacing. Pulmonary diastolic pressure, an indicator of the left atrial pressure, was higher during ventricular pacing than during the other pacing modes. Again this is probably a result of atrioventricular asynchrony. Loss of atrial function can significantly increase mean atrial pressure and pulmonary congestion. ${ }^{11}$

Systolic blood pressure decreased and diastolic blood pressure increased to about the same extent during the different pacing modes. The increase in diastolic blood pressure during pacing is caused by deterioration of left ventricular systolic function. ${ }^{12}{ }^{13}$

Coronary sinus oxygen saturation, coronary blood flow, and myocardial oxygen consumption were the same during the three pacing modes. Cardiac efficiency tended to be different during the three pacing modes; but this difference was not statistically significant. Cardiac efficiency tended to be lower during ventricular pacing, but this was the result of the lower cardiac output during ventricular pacing.

\section{COMPARISON WITH PREVIOUS STUDIES}

Kristensson et al studied 13 patients with ischaemic heart disease and permanent pacemakers. ${ }^{14}$ They used bicycle ergometry to compare how ventricular inhibited and atrial synchronous ventricular inhibited modes for a maximal synchronous rate affected maximal exercise capacity and angina. Atrial pacing increased exercise capacity without increasing angina. Kenny et al studied 10 patients with angina and permanent pacemakers who were randomly allocated to one month in each of three pacing modes: ventricular pacing at 70 beats/min, atrioventricular synchronous pacing with an upper rate 150 beats $/ \mathrm{min}$, and atrioventricular synchronous pacing with an upper rate 100 beats $/ \mathrm{min} .{ }^{15}$ At the end of the month the patients underwent an exercise test and their clinical state was evaluated. The atrioventricular synchronous mode with an upper rate of 100 beats/min was the preferred pacing mode because it was associated with less angina pain and fewer symptoms.

Rosenqvist et al compared the relative haemodynamic importance (at rest and during exercise) of atrial demand pacing with sequential atrioventricular sensing pacing and ventricular demand pacing in 12 patients (some with ischaemic heart disease) with intact atrioventricular conduction and atrioventricular sequential permanent pacemakers. ${ }^{16}$ In each patient the paced rate was the same for all three modes at rest and during exercise. They showed that normal ventricular activation with atrial pacing during rest and submaximal exercise improved left ventricular systolic performance more than either ventricular or atrioventricular sequential pacing. 
Nordlander et al studied eight patients with atrioventricular universal pacemakers. ${ }^{17}$ They investigated haemodynamic function, myocardial oxygen consumption, and cardiac output at rest and during exercise during ventricular inhibited and atrioventricular modes of pacing. Systemic and pulmonary pressures and myocardial blood flow and myocardial oxygen consumption at rest and during exercise were similar with both pacing modes. Cardiac output, however, increased more during atrioventricular pacing than during ventricular inhibited pacing.

Our study and that of Nordlander et al are different. Nordlander et al studied patients during exercise, whereas we studied our patients only during pacing at rest. Nordlander et al's patients had permanent pacemakers and ours had coronary artery disease and were studied during temporary pacing. Also the heart rates in the Nordlander study were not the same as during our different pacing tests. None the less, our results and those of Nordlander et al showed that coronary blood flow and myocardial oxygen consumption were the same during the different pacing modes whereas the cardiac output was reduced during ventricular pacing. Cardiac efficiency was about the same during the different modes of pacing, with a tendency to be lower during ventricular pacing: this was attributed to the development of lower cardiac output during rapid ventricular pacing in patients with coronary artery disease.

Boerth et al studied normal dogs during atrial and right ventricular pacing and showed that myocardial oxygen consumption was the same during the two pacing modes whereas cardiac efficiency was lower during ventricular pacing. ${ }^{5}$ Baller et al studied normal dogs at the same heart rates during atrial, atrioventricular, and ventricular pacing and showed that myocardial blood flow was the same during all three pacing modes. ${ }^{18}$ However, myocardial oxygen consumption was higher during ventricular than during atrial pacing whereas there was no difference between ventricular and atrioventricular pacing. Cardiac efficiency was lower during ventricular than atrial and atrioventricular pacing. The increase in myocardial oxygen consumption during ventricular and atrioventricular pacing could be the result of the asynchronicity of ventricular contraction, the incomplete relaxation, or predominantly fatty acid metabolism, mediated by baroreceptors and a fall in blood pressure after the onset of pacing which increases catecholamine concentrations. A possible mechanism to explain the apparently more economic state of the myocardium during atrial pacing compared with other pacing modes may be a reduction in sympathetic tone mediated by baroreceptors after an initial rise in blood pressure caused by frequency inotropism.

Recently Ono et al tried to determine whether left bundle branch block induced by electrical stimulation in dogs caused abnormal myocardial perfusion and ischaemia, and to elucidate its mechanism. ${ }^{19}$ They showed that flow in the left anterior descending coronary artery and the lactate extraction rate were not significantly changed by the altered ventricular activation. These results are in accord with our results.

\section{LIMITATIONS OF THE STUDY}

More than $30 \%$ of the patients were paced for less than the 5 minutes specified in the study design. The shorter atrioventricular delay we used during the atrioventricular pacing may have some beneficial effects on myocardial metabolism. ${ }^{2021}$ It might have been better to study patients with long PR intervals.

Our data are not relevant to ambulatory patients with coronary artery disease. We did not study the long-term effects of the different pacing modes in our patients.

\section{IMPLICATIONS OF THE STUDY}

We conclude that atrial, atrioventricular, and ventricular pacing have similar short-term effects on myocardial oxygen consumption and cardiac efficiency in patients with coronary artery disease, though ventricular pacing has a smaller effect on cardiac output. This factor should be considered when a permanent pacemaker is to be implanted in patients with coronary artery disease. More studies are needed to elucidate the present results and to investigate the long-term effects of the different pacing modes on cardiac energetics.

1 Sowton E. Haemodynamic studies in patients with artificial pacemakers. Br Heart $\mathcal{f} 1964 ; 26: 737-46$

2 Kruse I, Arnman K, Conradson T-B, Ryden L. A comparison of the acute and long-term hemodynamic effects of ventricular inhibited and atrial synchronous ventricula nhibited pacing. Circulation 1982;65:846-55.

3 Badke FR, Boinay P, Covall JW. Effects of ventricular pacing on regional left ventricular performance in the dog. Am $\mathcal{F}$ Physiol 1980;238:H858-H867.

4 Narahara KA, Blethel ML. Effect of rate on left ventricular volumes and ejection fraction during chronic ventricula pacing. Circulation 1983;67:323-9.

5 Boerth RC, Covell JW. Mechanical performance and efficiency of the left ventricular stimulation. $A m \mathcal{F}$ Physio 1971;221:1686-91.

6 Kralios AC, Tsagaris TJ. Effect of activation sequence on $\mathrm{MVO}_{2}$ before and after coronary ligation. $\mathrm{Am} \mathcal{F}$ Physiol 1978;234: $\mathrm{H} 260-\mathrm{H} 265$.

7 LaFarge CG, Miettinen OS. The estimation of oxygen consumption. Cardiovasc Res 1970;4:23-30.

8 Baim DS, Rothman MT, Harrison DC. Improved catheter for regional coronary sinus flow and metabolic studies. Am $\mathcal{F}$ Cardiol 1980;46:997-1000.

9 Pehrsson SK, Astrom H. Left ventricular function after long-term treatment with ventricular inhibited compared to atrial triggered ventricular pacing. Acta Med Scand 1983;214:295-304

10 Nordlander R, Pehrsson SK, Astrom H, Karlsson J. Myocardial demands of atrial-triggered versus fixed-rate ventricular pacing in patients with complete heart block. PACE 1987;10:1154-9.

11 Buckingham TA, Janosik DL, Pearson AC. Pacemaker hemodynamics: clinical implications. Prog Cardiovas Dis 1992;34:347-66.

12 Akhras F, Jackson G. Raised exercise diastolic blood pressure as indicator of ischaemic left ventricular dysfunction. Lancet 1991;337:899-900

13 Paraskevaidis IA, Kremastinos DT, Kassimatis AS, et al. Increased response of diastolic blood pressure to exercise in patients with coronary artery disease: an index of in patients with coronary artery disease: an index of 507-11.

14 Kristensson BE, Arnman K, Ryden L. Atrial synchronous ventricular pacing in ischaemic heart disease. Eur Heart $f$ 1983;4:668-73.

15 Kenny RA, Ingram A, Mitsuoka T, Walsh K, Sutton R. Optimum pacing mode for patients with angina pectoris. Optimum pacing mode for

16 Rosenqvist M, Isaaz K, Botvinick EH, Dae MW, Cockrell J, Abbott JA, et al. Relative importance of activation sequence compared to atrioventricular synchrony in left ventricular function. Am 7 Cardiol 1991;67:148-56.

17 Nordlander R, Pehrsson SK, Astrom H, Karlsson J. Myocardial demands of atrial-triggered versus fixed-rate ventricular pacing in patients with complete heart block. PACE 1987;10:1154-9. 
18 Baller D, Wolpers HG, Zippel J, Bretschneider HJ, Hellige $G$. Comparison of the effects of right atrial, right ventricular apex and atrio-ventricular sequential pacing on ular apex and atrio-ventricular sequential pacing on
myocardial oxygen consumption and cardiac efficiency: myocardial oxygen consumption and cardiac efficiency

19 Ono S, Nohara R, Kambara H, Okuda K, Kawai C. Regional perfusion and glucose metabolism in experimental left bundle branch block. Circulation 1992;85:
$1125-31$.

20 Ritter P, Daubert C, Mabo P, Descaves C, Gouffault J. Haemodynamic benefit of a rate-adapted A-V delay in dual chamber pacing. Eur Heart ₹ 1989;10:637-46.

21 Theodorakis G, Kremastinos D, Markianos M, et al. C $A M P$ and ANF levels in VVI and DDD pacing with different AV delays during daily activity and exercise. PACE 1990;13:1773-8.

\title{
SHORT CASES IN CARDIOLOGY
}

\section{Value of multiplane transoesophageal echocardiography in recurrent atrial myxoma}

\author{
A S Brown, $\mathrm{H}$ Why, $\mathrm{M} J$ Monaghan
}

Department of
Cardiology,Kings
College Hospital,
London
A S Brown
H Why
M J Monaghan
Correspondence to:
Mr M J Monaghan,
Department of Cardiology,
Kings College Hospital,
Denmark Hill,
London SE5 9RS.

Denmark Hill,
A 26 year old woman was referred to the cardiology outpatient department with occasional atypical chest pain. Seven years earlier she had had a left atrial myxoma removed at another hospital and had been lost to follow up.

Transthoracic echocardiography (TTE) showed a mobile mass in the left atrium but the exact site of the tumour pedicle was undefined (fig 1A). We then examined her by mul-

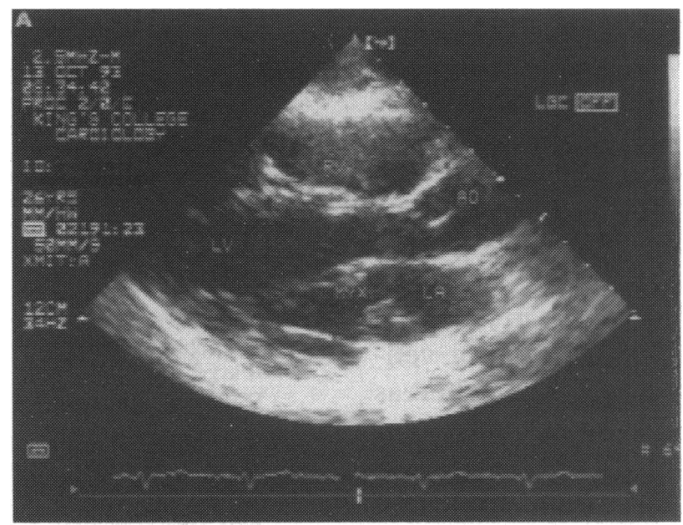

Figure 1A TTE showing the left atrial myxoma (myx), aortic root $(A o)$, left atrium $(L A)$, right atrium $(R A)$, right ventricle $(R V)$ and left ventricle $(L V)$.

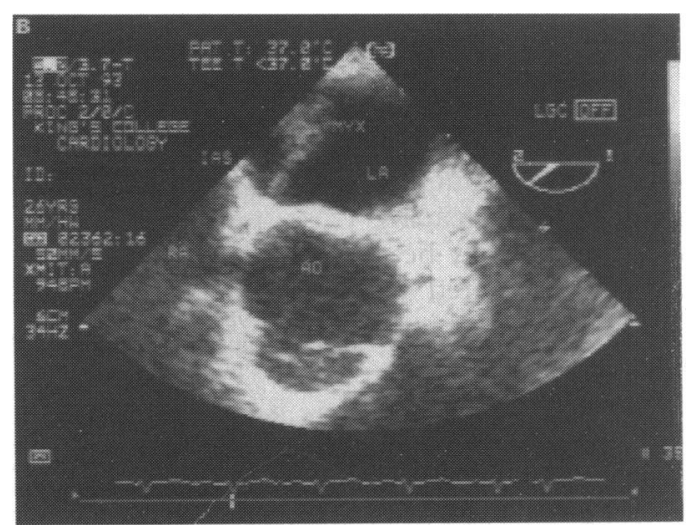

Figure 1B TOE with the transducer rotated to $33^{\circ}$ showing the attachment of the atrial myxoma to the interatrial septum (IAS). tiplane transoesophageal echocardiography (TOE). In the monoplane mode $\left(0^{\circ}\right)$ a globular tumour within the left atrium was visualised. When we adjusted the image plane to $33^{\circ}$ the tumour and its pedicle, attached to the interatrial septum, were clearly delineated (fig 1B). Further rotation of the transducer scan plane to $130^{\circ}$ showed several frond-like processes loosely attached to the main bulk of the tumour and prolapsing through the mitral valve. This detail of the tumour morphology was not readily appreciated on the TTE or TOE images in the monoplane mode and required specific angulations of the scan plane. The TOE findings prompted emergency cardiac surgery. At operation the multiplane images were confirmed and tumour was clearly seen arising from the upper edge of the previous scar, implying that local recurrence not seeding had occurred at the initial operation. She recovered uneventfully and was discharged to routine follow up.

The reported recurrence rate for sporadic atrial myxomas is $1-5 \% .{ }^{1}$ Because cardiac myxomas may be associated with life-threatening or fatal complications patients need long-term routine follow up by TTE after the resection of a myxoma. Once a cardiac myxoma has been diagnosed, TOE should be performed before operation to delineate precisely the tumour anatomy and exclude lesions elsewhere. The first generation of transoesophageal probes only imaged the heart in the transverse plane. Monoplane TOE has many advantages over $\mathrm{TTE}^{2}$ and this case shows that the recent development of multiplane transoesophageal probes offers additional benefits.

We thank Dr D Jewitt FRCP and Mr M Marrinan FRCS for their help and advice. This patient was under their care. ASB is a British Heart Foundation Junior Research Fellow.

1 McCarthy PM, Piehler JM, Schaff HV, Pluth JR, Orszulak TA, Vidaillet HJ, Carney JA. The significance of multiple, TA, Vidaillet HJ, Carme recurrent, and complex cardiac

2 Engbergding R, Daniel WG, Erbel R, Kasper W, Lestuzzi C, Curtius JM, et al. Diagnosis of heart tumours by C, Curtius JM, et al. Diagnosis of heart tumours by in 154 patients. Eur Heart 7 1993;14:1223-8. 
bradycardias and tachycardias and good working practice guidelines issued. Efforts in better education continue and to this end a full day programme will be held on 17 October 1994 to provide an update on all aspects of tachycardias and bradycardias and their treatment. Further information on this meeting, to be held in London, can be obtained from the BPEG office at 9 Fitzroy Square, London W1P 5AH (tel: 071636 5994)."

British Society of Echocardiography Mark Monaghan writes: "The British Society of Echocardiography has been going through a very busy period. We had a highly successful session during the Torquay meeting. Two debates were held on controversial topics in echocardiography, which proved to be highly entertaining and lively. Undoubtedly, this is a formula that we shall repeat.

Plans are well under way for our Autumn meeting, to be held at the Bedford Hotel in Brighton on Friday 25 and Saturday 26 November 1994. The first day will consist of presentations of abstracts (the closing date for receipt of abstracts is 2 September 1994). These abstracts will be published in Echocardiography 1995-a supplement to the British Heart fournal. On Saturday 26 November there will be a series of more practically orientated lectures, covering topics such as the diagnosis of pericardial disease and aortic dissection. Surgeons, cardiologists, and echocardiographers are all contributing to these topics and we are anticipating another very lively meeting.

We plan to hold the first of our proficiency level assessments during our Autumn meeting. These will include multiple choice questions and video tapes, etc., for those candidates wishing to apply for BSE proficiency level accreditation. In addition, candidates will have to complete a log book of completed cases. However, the log book does not have to be finished before the assessment is taken.

We have made some representations to the British Cardiac Society about the guidelines for specialist training in cardiology. We are pleased to see echocardiography given appropriate prominence in these recommendations. However, we would like to find some common ground on recommended numbers of cases and assessments. No doubt, this will be an ongoing discussion.

As previously mentioned, preparation of the next edition of our supplement to the British Heart fournal is already well advanced. Various articles, which will all be peer reviewed, are being prepared in addition to the abstracts from our Autumn meeting.

Our new membership administrator has a new computer system and database which will allow us to deal with our membership records more efficiently and also to store information such as training accreditation.

We are also planning a joint meeting with BCIS on interventional ultrasound. This will cover topics such as valvuloplasty, intravascular ultrasound, Doppler flow wire, etc. More details of this meeting will follow.

Finally, we have moved our annual general meeting to coincide with our Autumn meeting. This avoids our taking up valuable time during the British Cardiac Society annual meeting".

\section{News from Europe}

Philip Poole-Wilson writes: "By the time this is being read, the Congress in Berlin will be over. The organisation of this Congress has been a particular challenge to the European Society of Cardiology because it is not only the XVIth Congress of the European Society of Cardiology but also the XIIth World Congress of Cardiology. World Congresses occur every four years and are the meetings of the International Society and Federation of Cardiology (ISFC). The current President is David Kelly from Sydney, Australia. In Berlin he will be succeeded by Eliot Rapport from the USA.

We must now look ahead to the Congress in Amsterdam on 20-24 August, 1995. The planning committee meets on 27 October 1995. If you have suggestions for the programme please pass them directly to ECOR, to the chairman of a working group or, if you wish, directly to me. I will act as postman. Abstracts need to be received by ECOR by 14 February 1995. Application forms can be obtained from ECOR. The address of ECOR is: European Heart House, 2035 route des Colles, Les Templiers-BP 179, 06093 Sophia Antipolis Cedex, France (tel: 0103392 947600; fax: 0103392 947601)."

\section{Forthcoming meetings}

The annual meeting of the British Nuclear Cardiology Group will be held on 12 December, 1994 at St Thomas' Hospital in London. The programme, which is based on the theme of "How we will assess reversible ischaemia in the year 2000 ", can be obtained from Dudley Pennell at the
Royal Brompton Hospital (tel: 071351 8810). Professor Mario Verani from Houston, Texas will be giving the keynote lecture.

D JOHN PARKER President,

British Cardiac Society

JOHN G F CLELAND Secretary, British Cardiac Society,

9 Fitzroy Square,$$
\text { Lomitom WIP } 5 A H
$$

NOTICE

The 1995 Annual Meeting of the British Cardiac Society will take place at the Conference Centre, Harrogate, West Yorkshire from 23 to 25 May.

\section{CORRECTION}

Short-term effects of right atrial, right ventricular apical, and atrioventricular sequential pacing on myocardial oxygen consumption and cardiac efficiency in patients with coronary artery disease.

Z S Kyriakides, A Antoniadis, E Iliodromitis, $N$ Michelakakis, D T Kremastinos (Br Heart f 1994;71:536-40). In the formula for myocardial oxygen consumption (p 537) the first variable was given as $\mathrm{CO}$ (cardiac output). It should have been myocardial blood flow. The correct formula is $\mathrm{MVO}_{2}=$ $\mathrm{MBF} \times\left(\right.$ arterial $\mathrm{O}_{2}$ saturation - coronary sinus $\mathrm{O}_{2}$ saturation $\times \mathrm{Hb} \times 1.36\left(\mathrm{ml} \mathrm{O}_{2} / \mathrm{min}\right)$, where $\mathrm{MBF}$ is the myocardial blood flow in $1 / \mathrm{min}$ and $\mathrm{Hb}$ is haemoglobin in $\mathrm{g} / 100 \mathrm{ml}$. 